Tohoku J. Exp. Med., 2008, 216, 197-204

\title{
Review
}

\section{Mesenteric Ischemia: Still a Deadly Puzzle for the Medical Community}

\author{
Michael Stamatakos, ${ }^{1}$ Charikleia Stefanaki, ${ }^{1}$ Dimitrios Mastrokalos, ${ }^{2}$ \\ Helen Arampatzi, ${ }^{3}$ Panagiotis Safioleas, ${ }^{1}$ Constantinos Chatziconstantinou, ${ }^{4}$ \\ Constantinos Xiromeritis ${ }^{5}$ and Michael Safioleas ${ }^{1}$ \\ ${ }^{1}$ Second Department of Propaedeutic Surgery, Medical School, University of Athens, Laiko \\ General Hospital, Athens, Greece \\ ${ }^{2}$ First Orthopaedical Department, Medical School, University of Athens, Hospital Attikon, Athens, \\ Greece \\ ${ }^{3}$ First Department of Obstetrics and Gynecology, Athens University Medical School, Alexandra \\ Hospital, Athens, Greece \\ ${ }^{4}$ Department of Radiology, Laiko General Hospital, Athens, Greece \\ ${ }^{5}$ First Department of Surgery, University of Athens Medical School, Laikon Hospital, Athens, \\ Greece
}

The main goal of this article is to update etiology, epidemiology, diagnosis, treatment and outcome of the various causes of mesenteric ischemia in order to elucidate its labyrinthine clinical riddle, by reviewing the current English medical literature. Mesenteric ischemia is a quite uncommon disorder, observed in the emergency department. It is a lifethreatening vascular emergency that requires early diagnosis and intervention to restore mesenteric blood flow and to prevent bowel necrosis and patient death. Consequently, it is a vital diagnosis to make because of its high mortality rate and its thorny complications. The underlying causes vary, and the prognosis depends on the specific findings during clinical examination. Vague and nonspecific clinical findings and limitations of diagnostic studies make the diagnosis a significant challenge. The prognosis of acute mesenteric ischemia of any type is grave. The complications following this medical jigsaw puzzle are also severe. Patients in whom the diagnosis is missed until infarction occurs have a mortality rate of $90 \%$. Even with good treatment, up to $50-80 \%$ of patients die. Survivors of extensive bowel resection face lifelong disability. Despite the progress in understanding the pathogenesis of mesenteric ischemia and the development of treatment modalities, the entity remains a diagnostic challenge for clinicians. Delay in diagnosis contributes to a high mortality rate. Early diagnosis and adequate treatment can improve the clinical outcome. Even if diagnostic modalities have improved since the first successful attempts to confront effectively this clinical entity, mesenteric ischemia still remains a lethal diagnostic enigma for the medical community. - Mesenteric Ischemia; thrombosis; bowel infarction; atherosclerosis; mesenteric venous thrombosis; mesenteric thromboendarterectomy.

Tohoku J. Exp. Med., 2008, 216 (3), 197-204.

(C) 2008 Tohoku University Medical Press

Received August 27, 2008; revision accepted for publication October 1, 2008.

Correspondence: Michael Stamatakos MD, PhD, 5 Valaoritou Ave. Ano Glyfada, 16674.

e-mail: stamatakosmih@yahoo.gr 
Mesenteric ischemia was first described in the 15th century by Antonio Beniviene. It is due to a reduction in intestinal blood flow, which is most commonly caused by occlusion, vasospasm, or hypoperfusion of the mesenteric vessels. The clinical consequences can be catastrophic, making rapid diagnosis and treatment mandatory (Boley et al. 1997). The first successful surgery to repair a case of acute mesenteric ischemia was performed by Elliot who, in 1895, resected a gangrenous bowel. The first successful embolectomy was performed in 1957. By 1960, the combination of heparin administration and bowel resection, when required, became the standard treatment for mesenteric venous thrombosis. In the 1970 s, the use of angiography in evaluation of acute mesenteric ischemia and the introduction of intra-arterial papaverine infusion, improved significantly the prognosis of patients. The increasing use of ultrasound and computer tomography scan since the 1980s has also helped to achieve an earlier diagnosis (Boley et al. 1997; Cleveland et al. 2002). Mesenteric ischemia is a relatively rare disorder; however nonspecific clinical findings and limitations of diagnostic studies make the diagnosis a significant challenge. Despite recent advances in diagnosis and treatment, mortality rates continue to remain high (Chang and Stein 2003; Oldenburg et al. 2004; Ujiki 2005).

\section{Pathogenesis}

Mesenteric ischemia is due to a reduction in intestinal blood flow, which is most commonly caused by occlusion, vasospasm, and/or hypoperfusion of the mesenteric vessels. The celiac axis, the superior and the inferior mesenteric artery supply the foregut, midgut, and hindgut, respectively. The intestine has a significant collateral circulation, which contributes to some protection from ischemia and is able to compensate up to approximately $75 \%$ in case of acute reduction in mesenteric blood flow for up to 12 hours, without creating substantial injury. Many communications exist within the mesentery to the superior mesenteric artery, and rectal branches offer communication of the visceral blood supply with the common blood supply. The watershed area, near the splenic flexure, is thought to be more susceptible to ischemia secondary to poor arterial flow (Griffiths 1961; Rosenblum et al. 1997; Czerny et al. 1997). Intestinal ischemia can be classified in acute and chronic, based upon the rapidity and the degree of blood flow compromise. Acute mesenteric ischemia refers to the sudden onset of intestinal hypoperfusion, which can be due to occlusive or nonocclusive obstruction of arterial or venous blood flow. Occlusive arterial obstruction is most commonly due to emboli or thrombosis of mesenteric arteries, while occlusive venous obstruction is most commonly due to thrombosis or segmental strangulation. Nonocclusive arterial hypoperfusion is most commonly due to primary splanchnic vasoconstriction. Chronic mesenteric ischemia (also called intestinal angina) refers to episodic or constant intestinal hypoperfusion, which usually develops in patients with mesenteric atherosclerotic disease. Emboli to the mesenteric arteries usually arise from a dislodged cardiac thrombus or can be septic emboli. This results in embolic acute mesenteric ischemia. The superior mesenteric artery is most commonly affected (Bingol et al. 2004). Thrombotic acute mesenteric ischemia is usually due to acute thrombus formation over a preexisting atherosclerotic lesion of the mesenteric artery, thus further aggravation of ischemia. Thrombosis often involves at least 2 of the major splanchnic vessels. Causes include: Atherosclerotic vascular disease, aortic aneurysm or dissection, arteritis, dehydration (Liu et al. 2000).

Non-occlusive mesenteric ischemia is the most common outcome in severe systemic illness with reduced cardiac output. Intestinal vasospasm also occurs after cocaine ingestion, ergot poisoning, digoxin use, and with alpha-adrenergic agonists. Other predisposingconditions include hypotension from cardiac heart failure, myocardial infarction, sepsis, aortic insufficiency, severe liver or renal disease, or recent major cardiac or abdominal surgery and the use of digitalis (Endress et al. 1992; Bassiouny 1997; Sudhakar et al. 1997; Cappell 1998; Liu et al. 2000; Schoots et al. 2004). Mesenteric venous thrombosis occurs in patients, who are found to have the following pre- 
disposing conditions: hypercoagulability (protein $\mathrm{C}$ and S or antithrombin III deficiency,) hematologic conditions (polycythemia vera) pregnancy, oral contraceptive use, malignancy, infections, portal hypertension, venous trauma (Zakhour et al. 1987; Harward et al. 1989; Grieshop et al. 1991; Gennaro et al. 1993; Cappell 1998; Liu et al. 2000; A ğaoğlu et al. 2005). The consequences of vascular occlusion depend on the vessels involved and the status of collateral channels (Brandt et al. 2000). Chronic mesenteric ischemia usually results from long-standing atherosclerotic disease of two or more mesenteric vessels. Nonatheromatous causes of chronic mesenteric ischemia include the vasculitis. Symptoms are caused by a gradual reduction of blood flow to the intestine that occurs during eating, since total blood flow to the intestine should increase by $15 \%$ during meals in order to compensate with the required intestinal functionality (Cappell 1998; Cleveland et al. 2002). It is obvious enough to understand the common place in these entities. The vast majority of cases are secondary to arterial and venous causes. All diseases and conditions that affect arteries, including atherosclerosis, arteritis, aneurysms, arterial infections, dissections, arterial emboli, and thrombosis, have occasionally reported to appear in the intestinal arteries.

\section{Epidemiology}

Currently, the overall prevalence of acute mesenteric ischemia is $0.1 \%$ of all hospital admissions. The exact prevalence of mesenteric venous thrombosis is unknown because many cases are presumed to manifest poor symptoms and resolve spontaneous. In a report from Madrid of 21 patients with superior mesenteric artery embolus with little delay in initiating maximal treatment, intestinal viability was achieved in $100 \%$ of patients whose duration of symptoms was shorter than 12 hours, $56 \%$ if it was $12-24$ hours, and only $18 \%$ if it was longer than 24 hours. Early recognition and treatment of non-occlusive mesenteric ischemia has been shown to reduce the mortality rate to $50-55 \%$. Mesenteric venous thrombosis has a 30-day mortality rate of 13-15\% (Lobo Martinez et al. 1993). Overall, the mortality rate from all causes of acute mesenteric ischemia averages $71 \%$, with a range of $59-93 \%$ (Rhee et al. 1994). Acute mesenteric ischemia is frequently considered a disease of people older than 50 years. Younger people with atrial fibrillation or risk factors for mesenteric venous thrombosis may present an episode of acute mesenteric ischemia (Huang et al. 2005).

\section{Presentation and clinical features}

The diagnosis of mesenteric ischemia may be overlooked because of the vague nature of the patients' symptoms. The most important finding is pain disproportionate to physical examination findings. Depending on the type of mesenteric ischemia, patients may present with a variety of signs and symptoms (Zakhour et al. 1987; Harward et al. 1989; Grieshop et al. 1991; Gennaro et al. 1993; Lobo Martíez et al. 1993; Rhee et al.1994; Brandt et al. 2000; Ağaoğlu et al. 2005; Huang et al. 2005). Acute arterial mesenteric ischemia typically has the most abrupt and painful presentation of all types. This is due to the rapid onset of occlusion and inability to form additional collateral circulation (Lobo Martíez et al. 1993). Often, vomiting and diarrhea (gut emptying) are observed. Patients are usually found to have a source of embolization or a recent myocardial infarction (with mural thrombus) (Lobo Martíez et al. 1993; Cappell 1998; Schoots et al. 2004). In thrombotic acute mesenteric ischemia, $20-50 \%$ of patients have a history of abdominal angina. Abdominal angina is a syndrome of postprandial abdominal pain starting soon after eating and lasting for up to 3 hours. Weight loss, "food fear, early satiety, and altered bowel habits may be present (Grieshop et al. 1991; Gennaro et al. 1993; A ğaoğlu et al. 2005). These patients have undergone a gradual progression of arterial occlusion and frequently have a better collateral supply. Bowel viability is better preserved, often leading to a less severe presentation than with embolic acute mesenteric ischemia. Past medical history reveals atherosclerotic disease at other sites or a previous aortic reconstruction. Non-occlusive mesenteric ischemia has 
been related to a sustained decrease in cardiac output, which may accompany acute myocardial infarction, hypovolemia and septicemia. Moreover, most of these patients are under prescription of digitalis. Patients may have had a prodrome of malaise and vague abdominal discomfort.

When infarction occurs, the patients develop increasing pain associated with vomiting. They may become hypotensive and tachycardic, with release of loose bloody stool (Bassiouny 1997). Mesenteric venous thrombosis is often observed in a much younger patient population than other types of acute mesenteric ischemia. Patients can present with an acute or subacute onset of abdominal pain. Typical symptoms of acute mesenteric ischemia may have been experienced for a prolonged period with gradual worsening. Many patients have risk factors for hypercoagulability: oral contraceptive use or deep vein thrombosis (Jona et al. 1974; Zakhour et al. 1987; Harward et al. 1989; Grieshop et al. 1991; Lobo Martíez et al. 1993; Hassan and Raufman 1999; Kumar et al. 2001). Chronic mesenteric ischemia may be presented with a history of postprandial pain, typically starting 20-30 minutes after their last meal, which may last up to 60-90 minutes. They may also report fear of eating and weight loss. As a result they develop limitation of food intake and may be severely malnourished upon presentation. The pain may occasionally be refractory to opioid analgesics or may be absent in $15-25 \%$ of cases. Prior episodes of similar pain related to meals (intestinal angina) may be reported. Associated gastrointestinal symptoms are common: Nausea, vomiting and diarrhea may occur in $50 \%$ of patients with mesenteric ischemia. Melena, hematochezia and occult blood loss is reported in some cases (Fink et al. 2000; Tambyraja 2003). Advanced ischemia may be signified by increasing abdominal distention, ileus, peritonitis, and shock (Moawad et al. 1997).

\section{Diagnosis}

No laboratory test is able to sufficiently rule in or rule out the diagnosis of mesenteric ischemia (Sreenarasimhaiah 2003). There are some labora- tory tests, essential for diagnosis, which should be ordered: Prothrombin time activated partial thromboplastin time, complete blood cell count, chemistry studies. Complete blood count may initially be within the reference range, but the white blood count eventually rises as the disease progresses. As shown in Table 1, laboratory findings in mesenteric ischemia are nonspecific and generally unreliable. Several studies have found that serum D-dimers may be used as an early marker for acute mesenteric ischemia, although it appears to be insensitive (Bötger et al. 1990; Seidel et al. 1999; Kurt et al. 2005; Altinyollar et al. 2006). Waiting for laboratory results should not delay radiographic studies if serious suspicion of acute mesenteric ischemia exists. Plain abdominal radiographs are generally normal or nonspecific and therefore should not be used to rule out mesenteric ischemia. Positive findings are usually late. Plain films are best used for rapid identification of intestinal obstruction or perforation and in order to hasten surgical intervention (Bötger et al. 1990). Computed angiography helps to evaluate acute mesenteric ischemia and to exclude other causes of abdominal pain and it has a sensitivity of $71-96 \%$ and a specificity of 92-94\%. Although still not considered the criterion standard compared with classic angiography, computed angiography is noninvasive and readily available. Arterial occlusion may show non-enhancement of vessels (Wiesner et al. 2003). Multidetector row computed tomography scan provides a detailed examination of the small bowel and mesenteric vessels (Kim et al. 2001). Studies have shown a sensitivity ranging from 96-100\% and specificity ranging from $89-94 \%$. Angiography is the criterion standard for diagnosis and is often an important part of treatment. Biplane aortography can be used to confirm the presence and extent of occlusive disease. Sensitivity is reported to be $88 \%$. Angiography has the additional advantage of therapeutic options, including intra-arterial administration of thrombolytic agents and papaverine. Computed tomography scan of the abdomen is the diagnostic test of choice in in mesenteric venous thrombosis. Last but not least ultrasonography has proved to 
TABLE 1. Diagnostic Tools-Findings

\begin{tabular}{|c|c|}
\hline Diagnostic Tool & Finding(s) \\
\hline Laboratory tests & $\begin{array}{l}\text { - Elevated hematocrit } \\
\text { - Moderately elevated amylase levels } \\
\text { - Metabolic acidosis } \\
\text { - Increased lactate levels }\end{array}$ \\
\hline Plain abdominal radiographs & $\begin{array}{l}\text { - Ileus } \\
\text { - Small bowel obstruction } \\
\text { - Edematous/thickened bowel walls } \\
\text { - Paucity of gas in the intestinal lumen } \\
\text { - Pneumatosis intestinalis } \\
\text { - Submucosal gas } \\
\text { - Thumbrinting } \\
\text { - Portal venous gas }\end{array}$ \\
\hline Computed angiography & - Non-enhancement of vessels \\
\hline Multidetector row computed tomography & $\begin{array}{l}\text { - Mesenteric arterial thrombus } \\
\text { - Mesenteric venous thrombus } \\
\text { - Mesenteric venous gas } \\
\text { - Pneumatosis intestinalis } \\
\text { - Bowel-wall thickening } \\
\text { - Increased or decreased enhancement of the bowel wall } \\
\text { - Bowel dilatation } \\
\text { - Mesenteric or perienteric fat stranding } \\
\text { - Ascites } \\
\text { - Pneumoperitoneum } \\
\text { - solid organ infarction. }\end{array}$ \\
\hline Angiography & $\begin{array}{l}\text { - Abrupt cutoff of the superior mesenteric artery } \\
\text { - Absence of collateral circulation } \\
\text { - Narrowing of the origins of multiple superior mesenteric artery } \\
\text { branches } \\
\text { - "String of sausages" sign }\end{array}$ \\
\hline Computed tomography & $\begin{array}{l}\text { - Thrombus in the superior mesenteric vein } \\
\text { - Reflux of contrast into the aorta } \\
\text { - Prolonged arterial phase with accumulation of contrast } \\
\text { - Thickened bowel walls }\end{array}$ \\
\hline Ultrasonography & $\begin{array}{l}\text { - Thrombus in the involved arteries or veins } \\
\text { - Absent flow in the involved arteries or veins }\end{array}$ \\
\hline
\end{tabular}

be very valuable. Duplex sonography is highly specific (92-100\%) but not as sensitive (70-89\%) compared with angiography. Ultrasound is considered a second-line study for acute mesenteric ischemia. It may show a thrombus or absent flow in the involved arteries or veins (Cooperman et al. 1980; Bowersox et al. 1991; Moneta et al. 1991; Redaelli et al. 1998).

\section{Treatment}

Definitive treatment is generally withheld until an etiology is determined (Kozuch et al. 2005). All efforts must be made to improve the patient's cardiovascular status. Cardiac monitoring is required. Vasopressors must be avoided because they tend to worsen ischemia. Oxygen, fluid resuscitation and blood products must be 
provided. A nasogastric tube should be inserted because it helps to relieve distension and allows evaluation for upper gastrointestinal bleeding. Intra-arterial papaverine during angiography can be used regardless of the etiology of the intestinal ischemia (Browder et al. 1986). Papaverine is infused directly into the superior mesenteric artery through the angiogram catheter and acts by relaxing vascular smooth muscle thus improving intestinal blood flow. Thrombolytics can also be infused through the angiogram catheter for selected patients with embolic acute mesenteric ischemia. Their administration should only be undertaken if peritonitis or other signs of bowel necrosis are absent. It must be started within 8 hours of symptom onset (Kozuch et al. 2005). The strategy for definite treatment depends strictly on etiology of the disease. Papaverine infusion, surgical embolectomy, and intra-arterial thrombolysis is the treatment of choice for embolic acute mesenteric ischemia (Lobo Martíez et al. 1993). Unless the involved bowel is clearly gangrenous, an attempt of reperfusion is necessary. Papaverine infusion and arterial reconstruction either through aortosuperior mesenteric arterial bypass grafting or through reimplantation of the superior mesenteric artery to the aorta are applied on the case of thrombotic acute mesenteric ischemia (Eker et al. 1999; Hladíket al. 2005). Papaverine infusion is the mainstay of treatment in non-occlusive mesenteric ischemia. In the case of mesenteric venous thrombosis: anticoagulation with heparin/warfarin either alone or in combination with surgery must be started immediately. If no signs of bowel necrosis exist, the patient may not even need an operation (Savassi-Rocha and Veloso 2002; Schoots et al. 2005). Exploratory laparotomy and resection of infarcted bowel is indicated. Anticoagulation with heparin should be continued for 6 weeks. Thrombectomy has little use in mesenteric venous thrombosis because it can only be performed if the thrombus is fresh. For chronic mesenteric ischemia: angioplasty with or without stent placement or surgical revascularization. A high rate of success is reported with percutaneous stent revascularization, although repeated inter- ventions may be necessary (Hansen et al. 1997; Mohammed et al. 2000; Milner et al. 2004). A second-look procedure 24-48 hours later is indicated whenever bowel of questionable viability is not resected. In patients with extensive bowel involvement, efforts must be made to retain every centimeter of viable bowel. Following reconstitution of arterial flow, the viability of the bowel is reassessed. The most reliable method of determining bowel viability is a second-look laparotomy (Landis et al. 2005).

Postoperatively, blood pressure, hemoglobin and cardiac status should be monitored. Heparin anticoagulation and antibiotics should be continued. Papaverine may be administered to reduce vasospasm (Ward et al. 1995; Brown et al. 2005).

\section{Complications}

Because of the high prevalence of atherosclerosis, one of the most common complications involves mesenteric ischemia. Postoperative mesenteric ischemia by identifying correctable coronary artery disease before the patient enters the operating room must be prevented. During the perioperative period, a Swan-Ganz catheter should be used to monitor fluid and cardiac function. Finally, when cross-clamping the supraceliac aorta, the anesthesiologist should be notified to use myocardial protective maneuvers and reduction of after load to maximize cardiac output (Klempnauer et al. 1997). Acute renal failure in the immediate postoperative period can be prevented by keeping the patient well hydrated and administering mannitol before the aorta is crossclamped. Other possible complications include bleeding, infection, bowel infarction, prolonged ileus, and graft infection. In conclusion, the complications are: Sepsis/septic shock, multiple system organ failure, bowel necrosis requiring resection, death (Ward et al. 1995).

\section{Prognosis}

The prognosis of acute mesenteric ischemia of any type is grave. Patients in whom the diagnosis is missed until infarction occurs have a mortality rate of $90 \%$. Even with good treatment, up 
to $50-80 \%$ of patients die. Survivors of extensive bowel resection face lifelong disability. In extensive small bowel resection, patients have severe diarrhea for a few weeks, but many appear to compensate after a few months. Patients who have had total small intestine resection need lifelong intravenous hyperalimentation (Chang et al. 2006). However, with rapid treatment, the mortality rate can be reduced considerably, and patients may be spared bowel resection (Klempnauer et al. 1997). When more than half of the bowel is removed, mortality rates of up to $80 \%$ have been reported (Ward et al. 1995). A recent review has shown that the prognosis of patients with acute mesenteric ischemia differs with respect to etiology. Mortality rates are highest for patients with arterial thrombosis (70-87\%), followed by non-occlusive mesenteric ischemia (70-80\%), arterial embolism (66-71\%), and venous thrombosis (44\%). It is essential to act early on clinical suspicion and not to wait for the development of hard evidence (Kihara et al. 1999; Wadman et al. 2000).

\section{References}

Ağaoğlu, N., Türkyilmaz, S., Ovali, E., Uçar, F. \& Ağaoğlu, C. (2005) Prevalence of prothrombotic abnormalities in patients with Acute Mesenteric Ischemia. World J. Surg., 29, 1135-1138.

Altinyollar, H., Boyabatli, M. \& Berberoğlu, U. (2006) Ddimer as a marker for early diagnosis of Acute Mesenteric Ischemia. Thromb. Res., 117, 463-467.

Bassiouny, H.S. (1997) Nonocclusive mesenteric ischemia. Surg. Clin. North. Am., 77, 319-326.

Bingol, H., Zeybek, N., Cingöz, F., Yilmaz, A.T., Tatar, H. \& Sen, D. (2004) Surgical therapy for acute superior mesenteric artery embolism. Am. J. Surg., 188, 68-70.

Boley, S.J., Brandt, L.J. \& Sammartano, R.J. (1997) History of mesenteric ischemia. The evolution of a diagnosis and management. Surg. Clin. North. Am., 77, 275-288.

Böttger, T., Schäfer, W., Weber, W. \& Junginger, T. (1990) Value of preoperative diagnosis in mesenteric vascular occlusion. A prospective study. Langenbecks Arch. Chir., 375, 278-282.

Bowersox, J.C., Zwolak, R.M., Walsh, D.B., Schneider, J.R., Musson, A., La Bombard, F.E. \& Cronenwett, J.L. (1991) Duplex ultrasonography in the diagnosis of celiac and mesenteric artery occlusive disease. J. Vasc. Surg., 14, 780-786.

Brandt, L.J. \& Boley, S.J. (2000) AGA technical review on intestinal ischemia. American Gastrointestinal Association Gastroenterology, 118, 954-968.

Browder, W., Cerise, E.J. \& Litwin, M.S. (1986) Impact of emergency angiography in massive lower gastrointestinal bleeding. Ann. Surg., 204, 530-536.
Brown, D.J., Schermerhorn, M.L., Powell, R.J., Fillinger, M.F. Rzucidlo, E.M., Walsh, D.B., Wyers, M.C., Zwolak, R.M. \& Cronenwett, J.L. (2005) Mesenteric stenting for chronic mesenteric ischemia. J. Vasc. Surg., 42, 268-274.

Cappell, M.S. (1998) Intestinal (mesenteric) vasculopathy. I. Acute superior mesenteric arteriopathy and venopathy. Gastroenterol. Clin. North. Am., 27, 783-825.

Chang, J.B. \& Stein, T.A. (2003) Mesenteric ischemia: acute and chronic. Ann. Vasc. Surg., 17, 323-328.

Chang, R.W., Chang, J.B. \& Longo, W.E. (2006) Update in management of mesenteric ischemia. World J. Gastroenterol., 12, 3243-3247.

Cleveland, T.J., Nawaz, S. \& Gaines, P.A. (2002) Mesenteric arterial ischaemia: diagnosis and therapeutic options. Vasc. Med., 7, 311-321.

Cooperman, M., Martin, E.W. Jr. \& Carey, L.C. (1980) Evaluation of ischemic intestine by Doppler ultrasound. Am.J. Surg., 139, 73-77.

Czerny, M., Trubel, W., Claeys, L., Scheuba, C., Huk, I., Prager, M. \& Polterauer, P. (1997) Acute Mesenteric Ischemia. Zentralbl. Chir., 122, 538-544.

Eker, A., Malzac, B., Teboul, J. \& Jourdan, J. (1999) Mesenteric ischemia after coronary artery bypass grafting: should local continuous intra-arterial perfusion with papaverine be regarded as a treatment? Eur. J. Cardiothorac. Surg., 15, 218-220.

Endress, C., Gray, D.G. \& Wollschlaeger, G. (1992) Bowel ischemia and perforation after cocaine use. A.J.R. Am. J. Roentgenol., 159, 73-75.

Fink, S., Chaudhuri, T.K. \& Davis, H.H. (2000) Acute Mesenteric Ischemia and malpractice claims. South. Med. J., 93, 210-214.

Gennaro, M., Ascer, E., Matano, R., Jacobowitz, I.J., Cunningham, J.N. Jr. \& Uceda, P. (1993) Acute Mesenteric Ischemia after cardiopulmonary bypass. Am. J. Surg., 166, 231-236.

Grieshop, R.J., Dalsing, M.C., Cikrit, D.F., Lalka, S.G. \& Sawchuk, A.P. (1991) Acute mesenteric venous thrombosis. Revisited in a time of diagnostic clarity. Am. Surg., 57, 573-577.

Griffiths, J.D. (1961) Extramural and intramural blood-supply of colon. Br. Med. J., 1, 323-326.

Hansen, K.J. \& Deitch, J.S. (1997) Transaortic mesenteric endarterectomy. Surg. Clin. North. Am., 77, 397-407.

Harward, T.R., Green, D., Bergan, J.J., Rizzo, R.J. \& Yao, J.S. (1989) Mesenteric venous thrombosis. J. Vasc. Surg., 9, 328-333.

Hassan, H.A. \& Raufman, J.P. (1999) Mesenteric venous thrombosis. South. Med. J., 92, 558-562.

Hladík, P., Raupach, J., Lojík, M., Krajina, A., Voboril, Z., Jon, B., Simkovic, D., Havel, E., Bis, J. \& Belobrádek, Z. (2005) Treatment of acute mesenteric thrombosis/ischemia by transcatheter thromboaspiration. Surgery, 137, 122-123.

Huang, H.H., Chang, Y.C., Yen, D.H., Kao, W.F., Chen, J.D., Wang, L.M., Huang, C.I. \& Lee, C.H. (2005) Clinical factors and outcomes in patients with Acute Mesenteric Ischemia in the emergency department. J. Chin. Med. Assoc., 68, 299-306.

Jona, J., Cummins, G.M. Jr., Head, H.B. \& Govostis, M.C. (1974) Recurrent primary mesenteric venous thrombosis. J.A.M.A., 227, 1033-1035.

Kihara, T.K., Blebea, J., Anderson, K.M., Friedman, D. \& Atnip, R.G. (1999) Risk factors and outcomes following revascularization for chronic mesenteric ischemia. Ann. Vasc. Surg., 13, 37-44. 
Kim, J.K., Ha, H.K., Byun, J.Y., Yang, S.K., Jung, H.Y., Min, Y.I., Kim, P.N., Lee, M.G. \& Auh, Y.H. (2001) CT differentiation of mesenteric ischemia due to vasculitis and thromboembolic disease. J. Comput. Assist. Tomogr., 25, 604-611.

Klempnauer, J., Grothues, F., Bektas, H. \& Pichlmayr, R. (1997) Long-term results after surgery for Acute Mesenteric Ischemia. Surgery, 121, 239-243.

Kozuch, P.L. \& Brandt, L.J. (2005) Review article: diagnosis and management of mesenteric ischaemia with an emphasis on pharmacotherapy. Aliment. Pharmacol. Ther., 21, 201-215.

Kumar, S., Sarr, M.G. \& Kamath, P.S. (2001) Mesenteric venous thrombosis. N. Engl. J. Med., 345, 1683-1688.

Kurt, Y., Akin, M.L., Demirbas, S., Uluutku, A.H., Gulderen, M., Avsar, K. \& Celenk, T. (2005) D-dimer in the early diagnosis of Acute Mesenteric Ischemia secondary to arterial occlusion in rats. Eur. Surg. Res., 37, 216-219.

Landis, M.S., Rajan, D.K., Simons, M.E., Hayeems, E.B., Kachura, J.R. \& Sniderman, K.W. (2005) Percutaneous management of chronic mesenteric ischemia: outcomes after intervention. J. Vasc. Interv. Radiol., 16, 1319-1325.

Liu, J.J. \& Ardolf, J.C. (2000) Sumatriptan-associated mesenteric ischemia. Ann. Intern. Med., 132, 597.

Lobo Martínez, E., Meroño Carvajosa, E., Sacco, O. \& Martínez Molina, E. (1993) Embolectomy in mesenteric ischemia. Rev. Esp. Enferm. Dig., 83, 351-354.

Milner, R., Woo, E.Y. \& Carpenter, J.P. (2004) Superior mesenteric artery angioplasty and stenting via a retrograde approach in a patient with bowel ischemia--a case report. Vasc. Endovascular. Surg., 38, 89-91.

Moawad, J. \& Gewertz, B.L. (1997) Chronic mesenteric ischemia. Clinical presentation and diagnosis. Surg. Clin. North. Am., 77, 357-369.

Mohammed, A., Teo, N.B., Pickford, I.R. \& Moss, J.G. (2000) Percutaneous transluminal angioplasty and stenting of coeliac artery stenosis in the treatment of mesenteric angina: a case report and review of therapeutic options. $J$. R. Coll. Surg. Edinb., 45, 403-407.

Moneta, G.L., Yeager, R.A., Dalman, R., Antonovic, R., Hall, L.D. \& Porter, J.M. (1991) Duplex ultrasound criteria for diagnosis of splanchnic artery stenosis or occlusion. $J$. Vasc. Surg., 14, 511-518.

Oldenburg, W.A., Lau, L.L., Rodenberg, T.J., Edmonds, H.J. \& Burger, C.D. (2004) Acute Mesenteric Ischemia: a clinical review. Arch. Intern. Med., 164, 1054-1062.

Redaelli, C.A., Schilling, M.K. \& Buchler, M.W. (1998) Intraoperative laser Doppler flowmetry: a predictor of ischemic injury in acute mesenteric infarction. Dig. Surg., 15, 55-59.

Rhee, R.Y., Gloviczki, P., Mendonca, C.T., Petterson, T.M., Serry, R.D., Sarr, M.G., Johnson, C.M., Bower, T.C., Hallett, J.W. Jr. \& Cherry, K.J. Jr. (1994) Mesenteric venous thrombosis: still a lethal disease in the 1990s. J. Vasc. Surg., 20, 688-697.

Rosenblum, J.D., Boyle, C.M. \& Schwartz, L.B. (1997) The mesenteric circulation. Anatomy and physiology. Surg. Clin. North. Am., 77, 289-306.

Savassi-Rocha, P.R. \& Veloso, L.F. (2002) Treatment of superior mesenteric artery embolism with a fibrinolytic agent: case report and literature review. Hepatogastroenterology, 49, 1307-1310.

Schoots, I.G., Koffeman, G.I., Legemate, D.A., Levi, M. \& van Gulik, T.M. (2004) Systematic review of survival after acute mesenteric ischaemia according to disease aetiology. Br. J. Surg., 91, 17-27.

Schoots, I.G., Levi, M.M., Reekers, J.A., Lameris, J.S. \& van Gulik, T.M. (2005) Thrombolytic therapy for acute superior mesenteric artery occlusion. J. Vasc. Interv. Radiol., 16, 317-329.

Seidel, S.A., Bradshaw, L.A., Ladipo, J.K., Wikswo, J.P. Jr. \& Richards, W.O. (1999) Noninvasive detection of ischemic bowel. J. Vasc. Surg., 30, 309-319.

Sreenarasimhaiah, J. (2003) Diagnosis and management of intestinal ischaemic disorders. B.M.J., 326, 1372-1376.

Sudhakar, C.B., Al-Hakeem, M., MacArthur, J.D. \& Sumpio, B.E. (1997) Mesenteric ischemia secondary to cocaine abuse: case reports and literature review. Am. J. Gastroenterol., 92, 1053-1054.

Tambyraja, A.L. (2003) Management of acute mesenteric ischaemia recommended strategy is misleading. B.M.J., 327, 396.

Ujiki, M. \& Kibbe, M.R. (2005) Mesenteric ischemia. Perspect. Vasc. Surg. Endovasc. Ther., 17, 309-318.

Wadman, M., Syk, I. \& Elmstahl, S. (2000) Survival after operations for ischemic bowel disease. Eur. J. Surg., 66, 872-877.

Ward, D., Vernava, A.M., Kaminski, D.L., Ure, T., Peterson, G., Garvin, P., Arends, T.W. \& Longo, W.E. (1995) Improved outcome by identification of high-risk nonocclusive mesenteric ischemia, aggressive reexploration, and delayed anastomosis. Am. J. Surg., 170, 577-580.

Wiesner, W., Khurana, B., Ji, H. \& Ros, P.R. (2003) CT of acute bowel ischemia. Radiology, 226, 635-650.

Zakhour, B.J. \& Dallis, D.J. (1987) Mesenteric venous thrombosis 1911 to 1984. Surgery, 101, 383-388. 